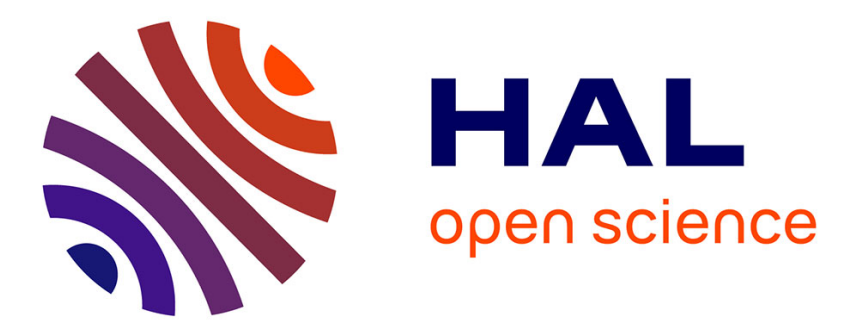

\title{
Future time perspective as predictor of cannabis use: Exploring the role of substance perception among French adolescents.
}

Thémis Apostolidis, Nicolas Fieulaine, Soulé Florence

\section{- To cite this version:}

Thémis Apostolidis, Nicolas Fieulaine, Soulé Florence. Future time perspective as predictor of cannabis use: Exploring the role of substance perception among French adolescents.. Addictive Behaviors, 2006, 31, pp.2339-2343. 10.1016/j.addbeh.2006.03.008 . halshs-00408110

\section{HAL Id: halshs-00408110 \\ https://shs.hal.science/halshs-00408110}

Submitted on 28 Jul 2009

HAL is a multi-disciplinary open access archive for the deposit and dissemination of scientific research documents, whether they are published or not. The documents may come from teaching and research institutions in France or abroad, or from public or private research centers.
L'archive ouverte pluridisciplinaire HAL, est destinée au dépôt et à la diffusion de documents scientifiques de niveau recherche, publiés ou non, émanant des établissements d'enseignement et de recherche français ou étrangers, des laboratoires publics ou privés. 


\section{Future time perspective as predictor of cannabis use: Exploring the role of substance perception among French adolescents.}

Thémis Apostolidis ${ }^{1}$, Nicolas Fieulaine $^{2}$, and Florence Soulé ${ }^{3}$

${ }^{1}$ (Corresponding author) Laboratoire de Psychologie Sociale, Université de Provence and INSERM U-379. Address: LPS, Université de Provence, 29 av. Robert Schuman, 13621 Aixen-Provence cedex, FRANCE. E-mail: aposto@up.univ-aix.fr. Telephone: ++334429538 15, Fax: +33442953720

2 GERA, Département de Psychologie Sociale, Université Lumière-Lyon 2. E-mail: Nicolas.Fieulaine@univ-lyon2.fr

${ }^{3}$ Association AMPTA, Marseille, FRANCE. E-mail: florencesoule@yahoo.fr. 


\begin{abstract}
This study explored the relation of Future time perspective (FTP) to cannabis use and tested the potential mediating role of cannabis perception, with a sample of 276 French adolescents (128 males and 148 females with a mean age of 15.6 years). FTP was assessed using ZTPI subscale, and cannabis perception was evaluated from a list of 9 items referring to a drug-oriented perception (DOP). Participants were also asked to report their cannabis use and level of use. Results showed that FTP acts as a significant predictor of cannabis use, and is significantly linked to DOP. Additionally, a strengthen relationship between DOP and cannabis use also appeared. Regression analyses showed that DOP acts as a mediator in the link between FTP and cannabis use. Although these findings confirm the protective role of FTP, they also suggest the indirect nature of this role and the importance of taking into account socio-cognitive dimensions related to substance use when analysing the complexity of contemporary cannabis use.
\end{abstract}

\title{
Keywords:
}

Cannabis use; Future time perspective; Substance perception; Young French adolescents. 


\section{Introduction}

Over the last decade in France, as in many other European countries, the use of cannabis among adolescents has considerably increased. French epidemiological surveys show that cannabis is the most commonly used illicit drug and estimate that the first consumption occurs about 15 years old and that by the end of adolescence, between 50 and $60 \%$ of 18 years old will have at least tried cannabis (Beck \& Legleye, 2003). In the French context, it appears important to take into account that, among adolescents, cannabis use has become "normalised", in the sense of being commonplace (Hammersley, Jenkins \& Reid, 2001). However, the way the cannabis is perceived is still a cause for much social debates about its definition as a "drug" (soft vs. hard) and its relations with the others licit and illicit substances (e.g., comparison between associated harmful effects and legal policies). Those controversial questions, grounded on the social context where use occurs, are significant for analysing psychosocial dynamic of consumption behaviours. Especially when considering that differential perceptions of the substance between cannabis users and non-users are also rooted in the labelling of cannabis as a drug (Dany \& Apostolidis, 2002). Given that perceptions and beliefs related to cannabis are important factors in substance use (e.g., Chabrol, Massot \& Mullet, 2004), thus, from a socio-cognitive perspective, substance labelling appears as a salient dimension for analysing contemporary cannabis use. This is particularly interesting within adolescent populations for whom the perception of cannabis as a drug or not could contribute to substance initiation and to the involvement in use.

In order to analyse substance use and abuse, many studies had underline the essential role of general personality variables for understanding those complex social behaviours. Among these variables, time perspective (TP) has been shown as dispositional construct underlying substance use behaviours. In this field, TP was often seen as playing an important role and was thus revealed as predictive of psychoactive substance consumption (Keough, Zimbardo \& Boyd, 1999; Levy \& Earleywine, 2004), and of cannabis use in particular (Wills, Sandy \& Yaeger, 2001). Above all, it appears from those researches that future orientation is significantly inversely related to substance use. Although a well-developed body of studies has demonstrated this relationship, few studies have investigated the link between TP and substance related cognitions. However, previous findings suggest that TP is related not only to 
substance use, but also to perceptions related to this behaviour (e.g., Apostolidis, Fieulaine, Simonin \& Rolland, in press).

In order to further our understanding of the ways by which time perspective, as a distal factor, operates in the process of substance use, it thus appears useful to examine the role played by a proximal factor as cannabis perceptions. Therefore, the current study tested how effect of future time perspective is mediated by the perceived substance in the context of early cannabis use among adolescents. At the level of the distal factor, future time perspective appears as relevant by its established role in substance use, and the hypothesis that future time perspective could be linked to substance perception has an evident theoretical interest for exploring the mechanisms through which TP might operate. On the other hand, the choosing mediator appeared as a relevant behaviourally specific immediate predictor (i.e., proximal factor) of early cannabis use. Lastly, the mediating hypothesis was based on previous crosssectional studies which suggest that the link between personality variables, such as time perspective (Wills, Sandy \& Yaeger, 2001) or impulsivity (Vangsness, Bry \& LaBouvie, 2005), and substance use could be mediated through proximal factors, such as ways of coping or learning factors as expectancies. Accordingly, we examined the potential mediating role of cannabis perception as a drug in the link between future time perspective and cannabis use. This prediction was tested in a sample of high school students assessed around 15 years old, a life period in which initiation to cannabis use seems to occur among French adolescents.

\section{Method}

\subsection{Participants and procedure}

A sample of adolescents was recruited from the 10th grade classrooms of a public general high school in Marseille (France). 304 pupils were currently registered at this level from which 280 were present the day when the data collection occurred. The research team administrated the questionnaires during normal class hours in group sessions of around twenty five participants. Students took part in this study on a voluntary basis and were invited to fill in the questionnaire individually. It was stressed that responses were completely anonymous and confidential. In order to reinforce the anonymous character of the survey, participants were invited to place their questionnaires into a common ballot box at the end of the session. 
279 students completed the questionnaire, from which 276 questionnaires were exploitable. The final sample was constituted by 128 males (46.4\%) and 148 females (53, $6 \%$ ), aged 13.5-18. The mean age was $15.6(S D=.72)$ and no differences were observed between males $(m=15.7, S D=.70)$ and females $(m=15.6, S D=.72)$.

\subsection{Measures}

\subsubsection{Future Time Perspective (FTP)}

FTP was measured using the FTP subscale of the ZTPI (Zimbardo \& Boyd, 1999) in its French validated version (Apostolidis \& Fieulaine, 2004). FTP subscale contains items referring to an attitude of planning for and achievement of future goals, and to conscientiousness. This temporal frame is represented by 12 items: I believe that a person's day should be planned ahead each morning; When I want to achieve something, I set goals and consider specific means of reaching those goals; It upsets me to be late for appointments; I make lists of things to do; I am able to resist temptations when I know there is work to be done; I complete projects on time by making steady progress; I keep working at a difficult uninteresting task if it will help me get ahead; If things don't get done on time, I don't worry about it; Meeting tomorrow's deadlines and doing others necessary work comes before tonight's play; I meet my obligations to friends and authorities on time; Before making a decision, I weigh the costs against the benefits. Respondents were asked to indicate on a 5point Likert-type scale the degree to which how each statement characterizes them, ranging from 1 (very uncharacteristic) to 5 (very characteristic). The scale score was calculated by the mean.

\subsubsection{Cannabis perception}

In order to explore the perceptions of cannabis as a drug, we created a questionnaire containing 9 items judged to be representative of drug-oriented perception of the substance. The statements were derived from previous exploratory findings concerning drugs and cannabis perceptions among adolescents and young adults, and from public debates throughout French society concerning cannabis (Dany \& Apostolidis, 2002). The selected items were: Cannabis is a drug; Cannabis leads to psychological dependence; Cannabis 
Future time perspective and cannabis use: substance perception as mediator

leads to physical dependence; Consuming cannabis can lead to an overdose; Cannabis consumption leads to the consumption of other drugs; Cannabis consumption involves health damages; Cannabis consumers suffer from psychological problems; Cannabis consumer is a drug-addict; Consuming cannabis is an act which harms the law and order. For each statement, participants were asked to rate their level of agreement on a 5-point Likert-type scale, ranging from 1 (strongly disagree) to 5 (strongly agree). This questionnaire allows calculating an indicator of participants' agreement with a drug-oriented cannabis perception by averaging the scores of the items.

\subsubsection{Cannabis Use}

This research used a self-report questionnaire to assess the respondents' cannabis use. First, participants were invited to indicate if they had already consumed cannabis (no/yes). Secondly, in order to assess the level of use in consumers, those who declared past consumption were asked to indicate how often they had used cannabis in the last year, month or day. This response format contained 5 levels of consumption; experimental (to have smoked cannabis but not during the last 12 months), occasional (to have smoked cannabis less than 10 times during the last 12 months), repeated (to have smoked cannabis less than 10 times during the last 30 days), regular (to have smoked cannabis more than 10 times during the last 30 days) and daily (to have smoked cannabis at least once per day), and was based on the patterns used in surveys conducted by the French Monitoring Centre for Drugs and Drugs Addiction (OFDT; cf. Beck \& Legleye, 2003).

\section{Results}

The alpha coefficient for FTP scale was calculated and appear to be satisfactory $(\alpha=$. $72, m=3.27, S D=.55$ ). Accordingly to previous findings, we observed a significant difference on FTP score between males $(m=3.18, S D=.53)$ and females $(m=3.35, S D=.56$; $F(1,275)=6.18, p=.013)$. Concerning cannabis perception, we conducted exploratory factor analysis on the items to examine the unidimensionality of the drug-oriented perception indicator (DOP). As expected, only one factor emerged, explaining $44.55 \%$ of the total variance $(K M O=.86)$. Additionally, the indicator appeared to have a satisfactory internal 
consistency $(\alpha=.84, m=3.43, S D=.75)$. No significant difference between sexes appeared on this indicator. In the total sample, $41.3 \%(N=114)$ of respondents reported having already used cannabis: $49.2 \%(N=63)$ of males and $34.4 \%(N=51)$ of females $\left(\chi^{2}=6.16, p=.01\right)$. Among them, the substance use level was: $26.3 \%(N=30)$ experimental, $39.5 \%(N=45)$ occasional, $11.4 \%(N=13)$ repeated, $11.4 \%(N=13)$ regular and $11.4 \%(N=13)$ daily. No differences between sexes appeared concerning these patterns of use $\left(\chi^{2}=3.46, n s\right)$.

The hypothesis of a mediating effect of DOP in the link between FTP and cannabis use (no/yes) was tested according to Baron \& Kenny (1986) criteria and using both logistic and linear regression analyses (controlled for age and sex). Table 1 recapitulates results from the two logistic regressions performed. The first one permitted to observe a significant negative link between FTP and cannabis use. In a separate linear regression analysis (controlled for age and sex), FTP appeared as a significant predictor of DOP $(\beta=.31, t=5.29, p<.0001$; Model: $\left.F(3,272)=10.64, p<.0001, R^{2}=.11\right)$. Thus, the more the participants are oriented towards FTP, the less they perceive cannabis as a drug. The results of the second logistic regression showed that the previously significant strength of the negative relationship between FTP and cannabis use become non significant when DOP is integrated into the regression equation. In addition, the Sobel test for the indirect effect was highly significant $(z=-4.15, p<.0001)$. Together, those results suggested the mediating role of DOP. Moreover, we could observed a significant increase in explained variance between the two equations (see Table $1 ; \Delta R^{2}=.29$, $F(1,271)=131.81, p<.0001)$, suggesting that DOP not only acts as a mediator, but also increases the predictive power of the model.

An analogous mediational hypothesis was tested concerning level of cannabis use, by examining the role of DOP in the link between FTP and level of use only among cannabis users $(\mathrm{N}=114)$. We used 3 linear multiple regression analyses (controlled for age and sex). The first one permitted to observe a significant negative link between FTP and level of cannabis use $\left(\beta=-.19, t=-2.03, p<.05\right.$; Model: $\left.F(3,110)=2.71, p<.05, R^{2}=.07\right)$. The second one confirmed the link between FTP and DOP in this sub-sample $(\beta=.33, t=3.79, p$ $<.001$; Model: $\left.F(3,110)=5.47, p<.001, R^{2}=.13\right)$. Finally the last one showed on one hand a highly significant positive link between DOP and level of use $(\beta=-.40, t=-4.33, p<$. 0001), and, on the other hand, that the link between FTP and level of use become non significant when DOP is integrated into the regression equation $(\beta=-.06, t=-.64, n s$; Model: $\left.F(4,109)=7.07, p<.0001, R^{2}=.20\right)$. Additionally, the Sobel test for the indirect effect 
appeared significant $(z=-2.91, p<.01)$. In a same way as previous analyses, the variance explained by the regression models increased significantly when DOP was added as mediator into the equation $\left(\Delta R^{2}=.13, F(1,109)=17.80, p<.0001\right)$.

\section{Discussion}

The findings of this study bring to underline several issues, which appear potentially crucial when analysing adolescents' cannabis use behaviours in the French context. Firstly, this study provides further support to the results already established in the literature concerning the negative relationship between FTP and reported cannabis use (Keough, Zimbardo \& Boyd, 1999). Secondly, we note that drug-oriented perception of cannabis is indicated here as an important factor negatively linked to substance initiation, using and abusing. Additionally, findings showed a link between FTP and this cognitive construct that had not previously been considered, future orientation thus appearing as associated with a more drug-oriented cannabis perception.

Beyond those direct relationships, our results support the idea of a mediating role of substance perception in the link between FTP and cannabis use, as hypothesized. Given the cross-sectional design of the study, it is not possible to draw conclusions on any causal relation or temporal ordering of FTP, substance perception and use. However, this research contributes to highlight the complexity of the process through which FTP operates on substance use and abuse behaviours, by showing that this relationship might be an indirect one. Mediational findings thus suggest that the TP's role could be developed into complex process, in which cognitive constructs as substance perception could intervene. According to our results, it might be suggested that a lower FTP involves a less drug-oriented cannabis perception that encourages cannabis initiation and use. This observation seems to be consistent with previous works examining the role of proximal factors in the link between personality variables and substance use (Wills, Sandy \& Yaeger, 2001; Vangsness, Bry \& LaBouvie, 2005). Moreover, the mediator under study contributes to explore the mechanisms behind the relation between FTP and cannabis use, which appear to be more complex than generally conceptualised. Mediating effect of cannabis perception as a drug may indicate that the primary link between FTP and substance use is through association with a non- 
specifically time-related cognitive construct. Then, taking into account the character of the proximal factor examined here (e.g., the labelling of cannabis as a drug), which is embedded in social and ideological debates, it appears that FTP can impact cannabis use through its role in how individuals posited regarding those debates concerning substance labelling. By this way, this study could offer crucial implications for future research by illustrating a mechanism by which a distal factor can be dependent of the social context through the mediating effect of a proximal socio-cognitive variable. In addition, findings suggest that such an emphasis on socio-cognitive dimensions may enhance predictive validity of the models elaborated for analysing the dynamics of complex social behaviours as substance initiation and use. This implies that for further understanding how personality variables, such as time perspective, affect substance use behaviours, it could be essential to consider potential mediating role of socio-cognitive constructs related to substance perception. However, further study must be undertaken to provide additional insight into this process, especially longitudinal and experimental studies which can make possible to establish causal and/or anteriority relations.

Apart from cross-sectional design, some other limitations of this study should be noted. Firstly, the nature of our sample doesn't allow generalisation. Secondly, the measures employed for substance use were all self-reported. Thirdly, as the measured cannabis perception deal with a construct which is socially and historical significant, findings are not automatically extensible to other substance related cognitions and contexts. Moreover, future studies must be carried in order to complete and extend these results. Despite these limitations, this study offers original findings, which emphasize the complexity of the FTP's role on substance use when taking into account socio-cognitive dimensions that reflect the socially embedded significations attached to the behaviours. The observed mediator effect highlights the need for future research aimed at a more detailed understanding of the relations between time perspective, substance use and related perceptions into a specific social context. Future comprehensive interventions in the field of cannabis use might be also enhanced further by considering the current findings. 
Future time perspective and cannabis use: substance perception as mediator

\section{References}

Apostolidis, T., \& Fieulaine, N. (2004). Validation française de l'échelle de temporalité The Zimbardo Time Perspective Inventory. European Review of Applied Psychology, 54, $207-$ 217.

Apostolidis, T., Fieulaine, N., Simonin, L., \& Rolland, G. (in press). Cannabis Use, Time Perspective and Risk Perception: Evidence of a moderating effect. Psychology \& Health.

Baron, R.M., \& Kenny, D.A. (1986). The moderator-mediator variable distinction in social psychological research: Conceptual, strategic, and statistical considerations. Journal of Personality and Social Psychology, 51, 1173-1182.

Beck, F., \& Legleye, S. (2003). Evolutions récentes des usages de drogues à 17 ans : ESCAPAD 2000-2002. Tendance, 29. Paris: OFDT.

Chabrol, H., Massot, E., \& Mullet, E. (2004). Factor structure of cannabis related beliefs in adolescents. Addictive Behaviors, 29, 929-933.

Dany, L., \& Apostolidis, T. (2002). A study on the social representations of drugs and cannabis: The issues and what is a stake for prevention. Santé Publique, 14, 335-344.

Hammersley, R., Jenkins, R., \& Reid, M. (2001). Cannabis use and social identity. Addiction Research \& Theory, 9, 133-150.

Keough, K.A., Zimbardo, P.G., \& Boyd, J.N. (1999). Who's smoking, drinking and using drugs? Time perspective as a predictor of substance use. Journal of Basic and Applied Social Psychology, 21, 149-164.

Levy, B., \& Earleywine, M. (2004). Discriminating reinforcement expectancies for studying from future time perspective in the prediction of drinking problems. Addictive Behaviors, 29, 181-190.

Vangsness, L., Bry, B.H., \& LaBouvie, E.W. (2005). Impulsivity, negative expectancies, and marijuana use: A test of the acquired preparedness model. Addictive Behaviors, 30, 1071-1076.

Wills, T.A., Sandy, J.M., \& Yaeger, A.M. (2001). Time perspective and early-onset substance use: A model based on stress-coping theory. Psychology and Addictive Behaviors, 15, 118-125.

Zimbardo, P.G., \& Boyd, J.N. (1999). Putting time in perspective: A valid, reliable individualdifferences metric. Journal of Personality and Social Psychology, 77, 1271-1288. 
Future time perspective and cannabis use: substance perception as mediator

Table 1.

Summary of logistic regression analyses predicting Cannabis Use.

\begin{tabular}{|c|c|c|c|c|}
\hline \multirow[b]{2}{*}{ Predictors } & \multicolumn{2}{|c|}{ Step 1} & \multicolumn{2}{|c|}{ Step 2} \\
\hline & $B(S E B)$ & $\operatorname{Exp}(B)(95 \% C I)$ & $B(S E B)$ & $\operatorname{Exp}(B)(95 \% C I)$ \\
\hline Age & $.43(.18)^{* *}$ & $1.54(1.07-2.22)$ & $.48(.22)^{*}$ & $1.62(1.04-2.50)$ \\
\hline Sex & $-.50(.26)$ & $.60(.36-1.01)$ & $-.53(.30)$ & $.58(.32-1.07)$ \\
\hline FTP & $-.69(.24)^{* *}$ & $.50(.31-.80)$ & $-.11(.30)$ & $.89(.49-1.63)$ \\
\hline DOP & -- & -- & $-1.83(.27)^{* * *}$ & $.16(.09-.27)$ \\
\hline \multicolumn{5}{|l|}{ Model } \\
\hline $\mathrm{Chi}^{2}$ (DL) & \multicolumn{2}{|c|}{$20.36(3)^{* * *}$} & \multicolumn{2}{|c|}{$88.55(4)^{* * *}$} \\
\hline$R^{2}$ (Nagelkerke) & \multicolumn{2}{|c|}{.10} & \multicolumn{2}{|c|}{.39} \\
\hline
\end{tabular}

$* p \leq .05 .{ }^{* *} p \leq .01 . * * * p \leq .001$.

Note: Cannabis use coded as 0 (no) and 1 (yes), Sex coded as 1 (male) and 2 (female). 